Document downloaded from:

http://hdl.handle.net/10251/157915

This paper must be cited as:

Garrido-García, EM.; Alfonso-Navarro, M.; Díaz De Greñu-Puertas, B.; Lozano-Torres, B.; Parra Álvarez, M.; Gaviña, P.; Marcos Martínez, MD.... (2020). Nanosensor for Sensitive Detection of the New Psychedelic Drug 25I-NBOMe. Chemistry - A European Journal. 26(13):2813-2816. https://doi.org/10.1002/chem.201905688

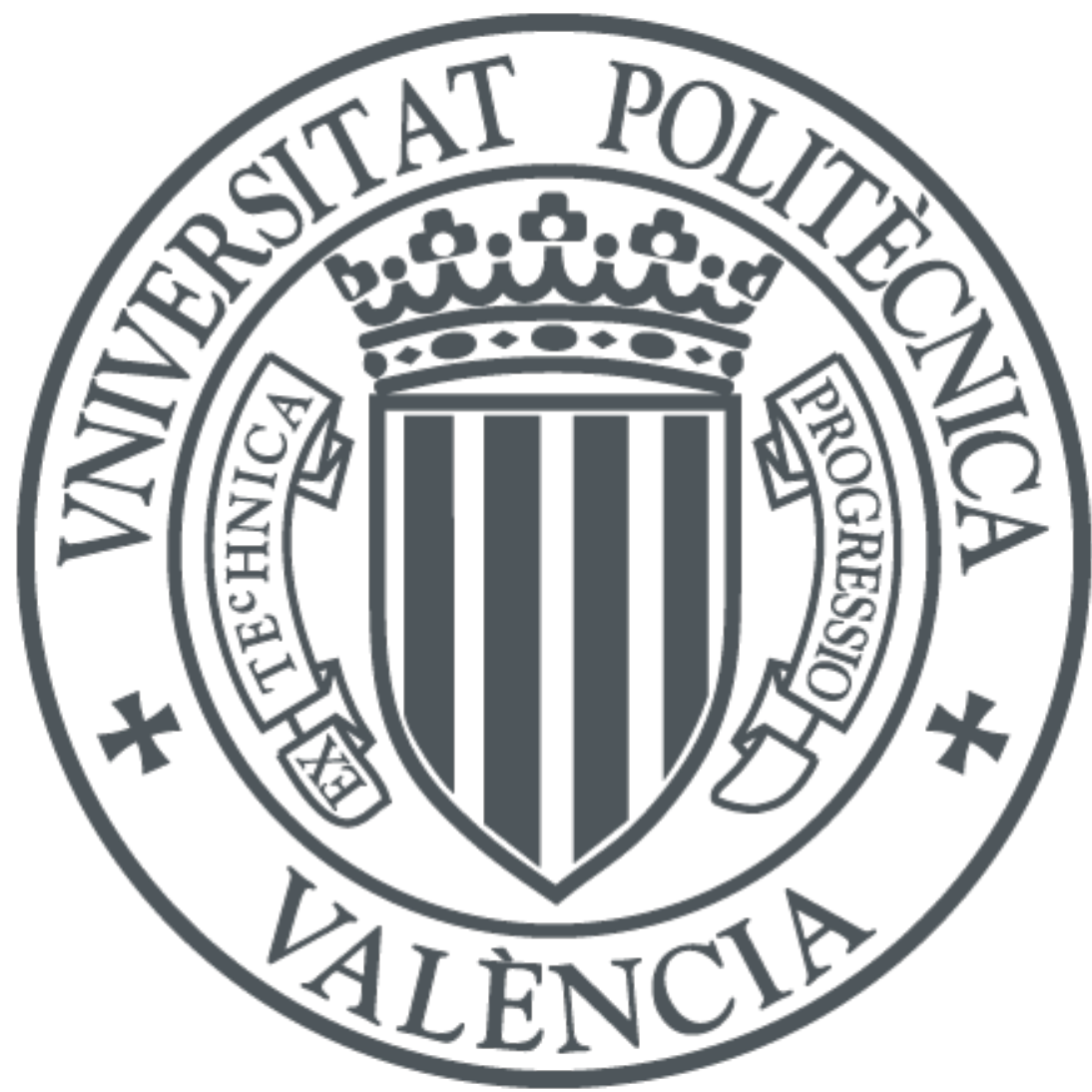

The final publication is available at

https://doi.org/10.1002/chem.201905688

Copyright John Wiley \& Sons

Additional Information

This is the peer reviewed version of the following article: E. Garrido, M. Alfonso, B. Díaz de Greñu, B. Lozano-Torres, M. Parra, P. Gaviña, M. D. Marcos, R. Martínez-Máñez, F. Sancenón, Chem. Eur. J. 2020, 26, 2813, which has been published in final form at https://doi.org/10.1002/chem.201905688. This article may be used for non-commercial purposes in accordance with Wiley Terms and Conditions for Self-Archiving. 


\title{
Nanosensor for sensitive detection of the new psychedelic drug 25I-NBOMe
}

\author{
Eva Garrido, ${ }^{[a],[b],[c],[d]}$ María Alfonso, ${ }^{[a],[c],[d]}$ Borja Díaz de Greñu, ${ }^{[a],[b],[c],[d]}$ Beatriz Lozano-Torres, ${ }^{[a],[b],[c],[d]}$ \\ Margarita Parra, ${ }^{[a],[b],[e]}$ Pablo Gaviña, ${ }^{[a],[b],[e]}$ M. Dolores Marcos, ${ }^{[a],[b],[c],[d],[f]}$ Ramón Martínez- \\ Máñez, ${ }^{\text {[a], }[\mathrm{b}],[\mathrm{c}],[\mathrm{rd},[\mathrm{f}]}$ and Félix Sancenón ${ }^{*[\mathrm{a}],[b],[c],[d],[f]}$
}
[a] E. Garrido, Dr. M. Alfonso, Dr. B. Díaz de Greñu, B. Lozano-Torres, Dr. M. Parra, Dr. P. Gaviña, Dr. M. D. Marcos, Prof. R. Martínez-Máñez, Dr. F. Sancenón
Instituto Interuniversitario de Investigación de Reconocimiento Molecular y Desarrollo Tecnológico (IDM)
Universitat Politècnica de València, Universitat Politécnica de València
Camino de Vera s/n, 46022, Valencia (Spain)
E-mail: rmaez@qim.upv.es; fsanceno@upvnet.upv.es
[b] E. Garrido, Dr. B. Díaz de Greñu, B. Lozano-Torres, Dr. M. Parra, Dr. P. Gaviña, Dr. M. D. Marcos, Prof. R. Martínez-Máñez, Dr. F. Sancenón CIBER de Bioingeniería, Biomateriales y Nanomedicina (CIBER-BBN) (Spain)
[c] E. Garrido, Dr. M. Alfonso, Dr. B. Díaz de Greñu, B. Lozano-Torres, Dr. M. D. Marcos, Prof. R. Martínez-Máñez, Dr. F. Sancenón Unidad Mixta de Investigación en Nanomedicina y Sensores.
Universitat Politècnica de València, Instituto de Investigación Sanitaria La Fe
Avenida Fernando Abril Martorell, Torre 106 A $7^{a}$ planta, 46026, Valencia (Spain)
[d] E. Garrido, Dr. M. Alfonso, Dr. B. Díaz de Greñu, B. Lozano-Torres, Dr. M. D. Marcos, Prof. R. Martínez-Máñez, Dr. F. Sancenón Unidad Mixta UPV-CIPF de Investigación en Mecanismos de Enfermedades y Nanomedicina
Universitat Politècnica de València, Centro de Investigación Príncipe Felipe
Carrer d'Eduardo Primo Yúfera, 3, 46012, Valencia (Spain)
[e] Dr. M. Parra, Dr. P. Gaviña
Departamento de Química Orgánica, Universitat de València
Doctor Moliner 50, Burjassot, 46100, Valencia (Spain)
[f] Dr. M. D. Marcos, Prof. R. Martínez-Máñez, Dr. F. Sancenón
Departamento de Química, Universitat Politècnica de València
Camino de Vera s/n, 46022, Valencia (Spain)

Supporting information for this article is given via a link at the end of the document.

\begin{abstract}
Herein, we present the synthesis, characterization and sensing behavior of a hybrid nanodevice for the detection of the potent abuse drug 25I-NBOMe. The system is based on mesoporous silica nanoparticles, loaded with a fluorescent dye, functionalized with a serotonin derivative and capped with the $5-\mathrm{HT}_{2 \mathrm{~A}}$ receptor antibody. In the presence of 25I-NBOMe the capping antibody is displaced leading to pore opening and rhodamine $B$ release. This delivery was ascribed to $5-\mathrm{HT}_{2 \mathrm{~A}}$ receptor antibody detachment from the surface due to its stronger coordination with 25I-NBOMe present in the solution. The prepared nanodevice allowed the sensitive (limit of detection of $0.6 \mu \mathrm{M}$ ) and selective recognition of the 25I-NBOMe drug (cocaine, heroin, mescaline, lysergic acid diethylamide, MDMA and morphine were unable to induce pore opening and rhodamine $B$ release). This nanodevice acts as a highly sensitive and selective fluorometric probe for the 25I-NBOMe illicit drug in artificial saliva and in sweets.
\end{abstract}

In the last years, the appearance and availability of new psychoactive substances (NPS) in the illicit market has increased exponentially, becoming a serious worldwide problem that concerns to governments and international institutions. Indeed, according to the last reports published, ${ }^{[1]} 275$ million people, approximately $5.6 \%$ of the global population used drugs, at least once, in 2016. Among NPS, hallucinogenic drugs are proliferating and gaining popularity.

Recently, a new synthetic family of $\mathrm{N}$ benzylphenethylamines (NBOMes) as hallucinogenic potent abuse drugs started to be available online. Normally, these drugs are consumed as a powder, in solution and in different supports such as blotting paper administered sublingually (in doses around $750 \mu \mathrm{g}){ }^{[2]}$ Moreover, these drugs have also been detected in adulterated commercial sweets (gummy bears), which are normally distributed in pubs. ${ }^{[3]}$
One of the most remarkable members, among NBOMes derivatives, is 25I-NBOMe, well-known by its street names of "Smiles", "Solaris", "N-Bomb" or "Wizard". Structurally, 25INBOMe is a phenethylamine derived from the $2 \mathrm{C}$ family of NBOMes in which the 2- and 5- positions of a benzene ring have been substituted by methoxy groups. 25I-NBOMe, as well as other members of the NBOMe family, acts as extremely potent and highly selective agonists of the serotonin $5-\mathrm{HT}_{2 \mathrm{~A}}$ receptor. ${ }^{[4]}$ This drug is considered as a highly powerful hallucinogen in humans, and among its main effects can be found euphoria, anxiety, paranoia, memory suppression or empathy enhancement. Furthermore, its consumption (common dosage between 0.2 and $1 \mathrm{mg})^{[5]}$ is associated with many toxicity and fatal cases published in the last years. ${ }^{[6]}$ All these issues make the detection of this drug highly important.

25I-NBOMe can be detected by several instrumental techniques such as HPLC-MS,${ }^{[7]}$ GC-MS ${ }^{[8]}$ differential pulse voltammetry, ${ }^{[9]}$ ATR-FTIR spectrometry ${ }^{[10]}$ and bioanalytical procedures. ${ }^{[11]}$ However, for most of these methods, samples must be moved to qualified laboratories, require the use of complex techniques and the supervision of trained personnel and cannot be applied to in situ or at site analysis. In order to overcome these typical drawbacks of classical analytical techniques, the development of chemo-fluorogenic probes has become a matter of concern for the rapid and easy detection of analytes. However, as far as we know, there are not reported optical probes for the detection of the new drug 25I-NBOMe.

Among different approaches to develop optical probes the use of hybrid organic-inorganic gated materials have been recently reported. These sensing hybrid probes are based on the use of a porous inorganic scaffold in which a reporter unit (usually a dye or a fluorophore) is stored and a bulky 
(supra)molecular ensemble is used as cap blocking the pores and inhibiting dye/fluorophore release. The capping ensemble is designed in such a way that interaction/coordination with a target analyte induces changes in its conformation/size/shape or is displaced, resulting in pore opening and dye/fluorophore release. One of the advantages of these sensing materials is the potential existence of amplification features. In particular, it has been demonstrated that the presence of few analyte molecules may induce the release of a relatively high amount of entrapped dye/fluorophore molecules. ${ }^{[12]}$ As support for the development of such sensing hybrid materials mesoporous silica nanoparticles (MSNs) have been used. The main advantages provided by MSNs are their high specific surface area, homogeneous porosity, high load capacity, tunable pore size $(2-10 \mathrm{~nm})$ and easy functionalization using well-known chemistries. ${ }^{[13]}$ Based on the above, we report herein the preparation of a selective and sensitive fluorogenic probe for the hallucinogen drug 25INBOMe.

The probe consists of MSNs loaded with rhodamine B, functionalized with a serotonin derivative (3) and capped with a polyclonal antibody of the $5-\mathrm{HT}_{2 \mathrm{~A}}$ receptor. The nanoparticles are designed to show "zero" release, yet open in the presence of the 25I-NBOMe drug. The base of the sensing mechanism arises from a competition between the grafted serotonin derivative and 25I-NBOMe for the coordination with the antibody of the $5-\mathrm{HT}_{2 \mathrm{~A}}$ receptor. The antibody is known to have more affinity for 25I-NBOMe than for the serotonin derivative and therefore the presence of 25I-NBOMe is expected to induce a displacement of the cap and selective dye delivery (Scheme 1).

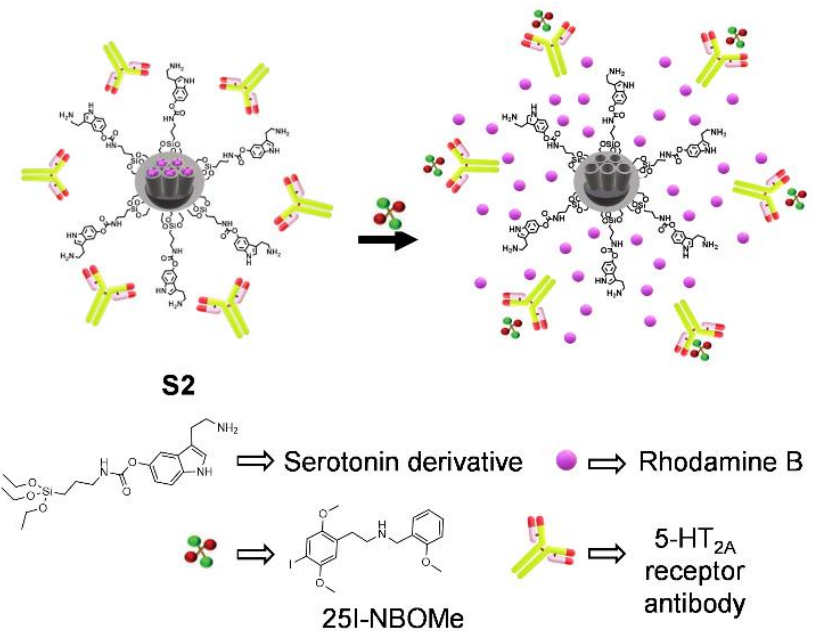

Scheme 1. Mechanism of release of solid S2 in the presence of 25I-NBOMe.

MSNs were synthesized by base-catalyzed sol-gel condensation of tetraethyl orthosilicate (TEOS) in the presence of hexadecyltrimethylammonium bromide $(\mathrm{CTABr})$ as structure directing agent following well-known pocedures. ${ }^{[14]}$ The pores of the MSNs were loaded with rhodamine B (solid S0) and the external surface of the nanoparticles was functionalized with the serotonin derivative 3 (Scheme 2, S1-Boc). The Boc protecting group from 3 was then removed using trifluoroacetic acid (TFA), giving rise to the solid $\mathbf{S 1}$. The final probe (S2) was obtained after stirring a suspension of $\mathbf{S} 1$ containing the antibody of the 5$\mathrm{HT}_{2 \mathrm{~A}}$ receptor (see experimental details in the $\mathrm{SI}$ ). Moreover, compound $\mathbf{3}$ was synthesized by the protection of the amino group of serotonin (1) with di-tert-butyl dicarbonate $\left(\mathrm{Boc}_{2} \mathrm{O}\right)$ to obtain $2^{[15]}$ that was further reacted with (3isocyanatopropyl)triethoxysilane (Scheme 2). Compound $\mathbf{3}$ was characterized by using magnetic resonance techniques such as ${ }^{1} \mathrm{H}-\mathrm{NMR}$ and ${ }^{13} \mathrm{C}-\mathrm{NMR}$ (Figures $\mathrm{S} 1-\mathrm{S} 2$ ). Furthermore, the nanoparticles were characterized by using standard techniques as powder X-ray diffraction (PXRD), transmission electron microscopy (TEM), $\mathrm{N}_{2}$ adsorption-desorption isotherms and elemental and thermogravimetric analyses (Figures S3-S6).

The response of the sensing material $\mathbf{S} 2$ to the "Smiles" drug was evaluated. Figure 1 shows the dye release profile (TRIS saline Buffer at $\mathrm{pH}$ 7.3) from $\mathbf{S 2}$ obtained in the absence and the presence of the drug. Dye delivery was followed measuring the fluorescence of the rhodamine $B$ at $572 \mathrm{~nm}$ at scheduled times in the solution. As can be seen, a large signal (i.e. dye delivery) was observed in the presence of 25I-NBOMe when compared with the same material in the absence of the drug. This confirms the preferential interaction of the antibody for 25I- NBOMe that results in pore opening and cargo release.

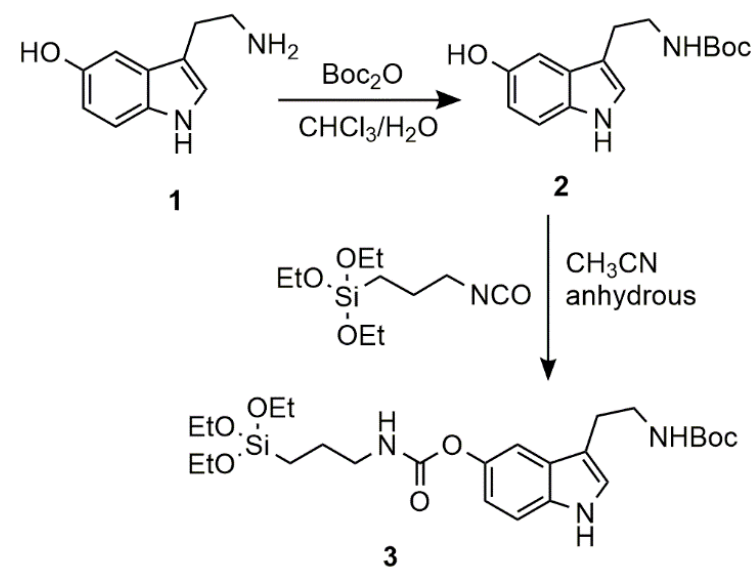

Scheme 2. Synthetic route used for the preparation of serotonin derivative 3 .

To further confirm that the $5-\mathrm{HT}_{2 \mathrm{~A}}$ antibody plays a key role in the gating mechanism, we also studied the delivery profiles of the uncapped solid $\mathbf{S} 1$ in the absence and presence of $25 \mathrm{I}$ NBOMe. In this case, a marked rhodamine $B$ release was observed in both cases (Figure S7).

The sensitivity of $\mathbf{S 2}$ towards the "Smiles" drug was also tested. In this case, dye delivery from $\mathbf{S} 2$ in TRIS saline buffer towards increasing concentrations of the drug was followed. Figure S8 shows the gradual rise in the fluorescent emission with increasing concentrations of "Smiles" (each point measured $30 \mathrm{~min}$ after addition). From the titration profile, a detection limit of $0.6 \mu \mathrm{M}$ for 25I-NBOMe was obtained. This value is enough to detect a common dose $(0.75 \mathrm{mg})$ even if diluted in $2 \mathrm{~L}$ of water.

The response of the antibody-capped solid $\mathbf{S 2}$ was also studied against other selected drugs (Scheme 3). In particular, we selected lysergic acid diethylamide (LSD) because "Smiles" drug is used as a substitute for LSD due to its cheaper cost and comparable effects. Mescaline was selected because it also belongs to NBOMe family. Finally, the other common drugs such cocaine, heroin, MDMA and morphine were included in the study since their consumption as psychoactive drugs is highly extended. For this study, solid S2 was suspended in TRIS saline buffer at pH 7.3 in the presence of a final concentration of $75 \mu \mathrm{M}$ of the drugs. As showed in Figure 2, after 20 min only 25I- 
NBOMe produces a remarkable enhancement in the emission fluorescence (at $572 \mathrm{~nm}$ ) when compared with the blank (absence of drugs, whereas other drugs induce none or a poor delivery. Besides, solid $\mathbf{S 2}$ can be stored dried at $4{ }^{\circ} \mathrm{C}$ for at least 1 month retaining, without dropping selectivity and sensitivity.

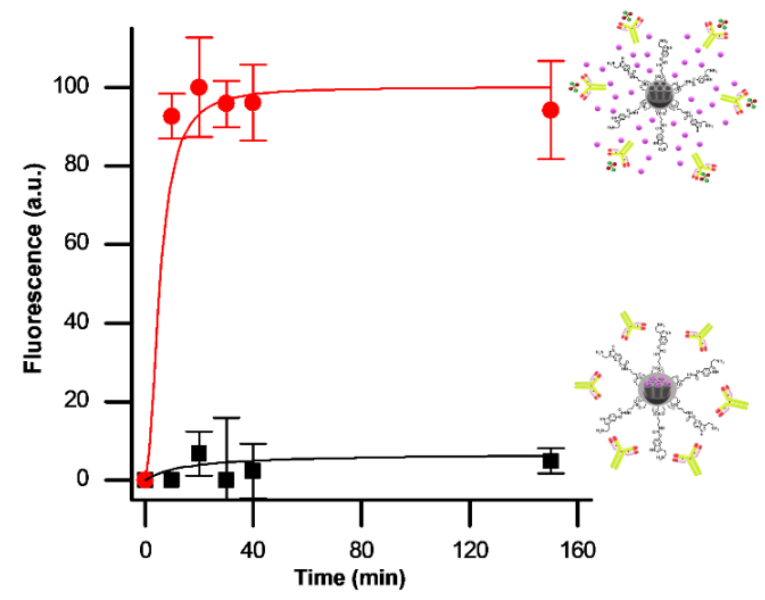

Figure 1. Release profile of rhodamine B from suspensions of solid $\mathbf{S} 2$ in TRIS saline Buffer at $\mathrm{pH} 7.3$, in the absence (black line) and in the presence (red line) of 25I-NBOMe $(300 \mu \mathrm{M})$. Error bars are expressed as $3 \sigma$.

In order to test the potential applicability of the probe in competitive environments, we tested the ability of $\mathbf{S} 2$ to detect 25I-NBOMe in artificial saliva and commercial sweets. For this purpose, we prepared artificial saliva and measured the controlled release of rhodamine B from S2 nanoparticles in the absence and in the presence of the drug. The results obtained are depicted in Figure S9, which shows that even in this competitive medium 25I-NBOMe induced a remarkable uncapping of the $\mathbf{S} 2$ probe. Additional studies indicated that in artificial saliva a detection limit of $0.9 \mu \mathrm{M}$ for 25I-NBOMe was obtained (Figure S10) which is a value comparable with that found in TRIS buffer solution.

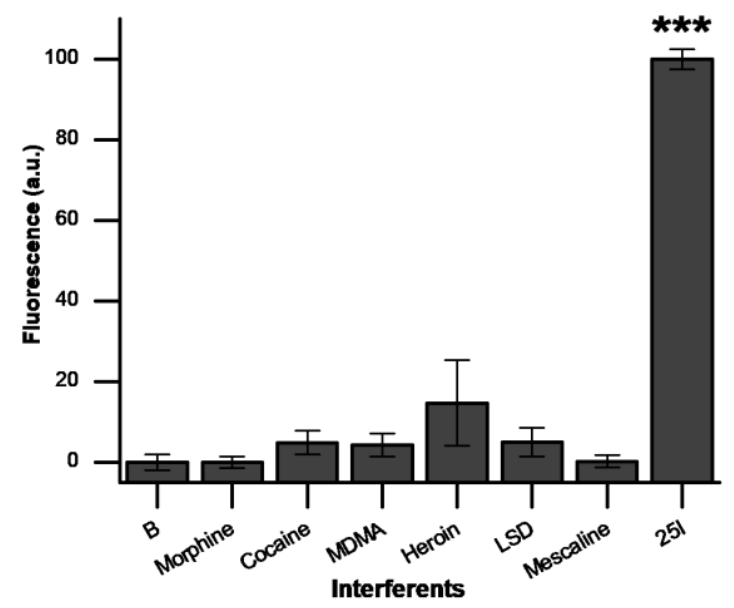

Figure 2. Released rhodamine B from solid $\mathbf{S 2}$ (measured as fluorescence intensity at $572 \mathrm{~nm}$ ) in the presence of $75 \mu \mathrm{M}$ of the indicated drugs in TRIS saline buffer at $\mathrm{pH} 7.3$ (after 20 min of addition). Error bars are expressed as $3 \sigma$ for three independent experiments $\left({ }^{* * *} p<0.0001\right)$.
For the detection of "Smiles" in adulterated candies with probe S2, a commercial sweet was adulterated with $5 \mathrm{mg}$ of the drug (Figure S11). The adulterated sweet was introduced in an erlenmeyer flask with $10 \mathrm{~mL}$ of $\mathrm{EtOH}$ and shaken at room temperature for 30 minutes to extract 25I-NBOMe. As shown in Figure 3 , rhodamine $B$ release is significantly higher when the candies are adulterated. Additional studies demonstrated that the probe does not respond to typically component of sweet such as tartrazine, starch, glucose, saccharose and jelly (Figure S12).<smiles>CCN(CC)C(=O)C1C=C2c3cccc4[nH]cc(c34)C[C@H]2N(C)C1</smiles>

Lysergic diamine acid (LSD)

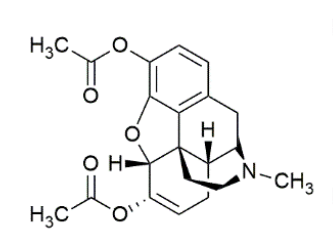

Heroin<smiles>CNC(C)Cc1ccc2c(c1)OCO2</smiles>

MDMA

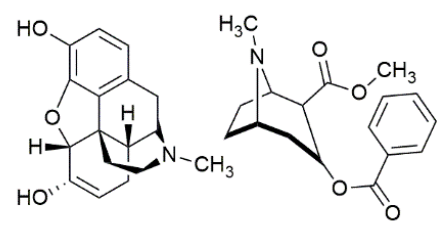

Morphine
Cocaine
Scheme 3. Chemical structure of the drugs used as interferents for selectivity studies.

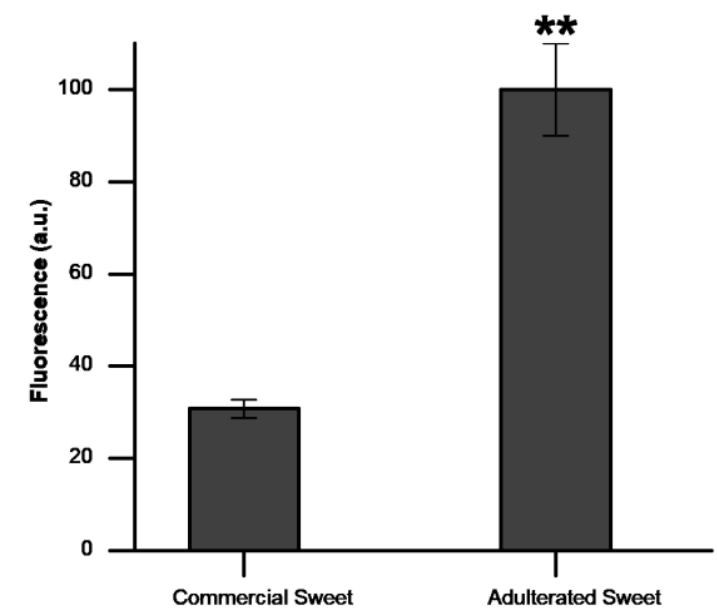

Figure 3. Fluorescence emission at $572 \mathrm{~nm}\left(\lambda_{\mathrm{exc}}=565 \mathrm{~nm}\right)$ associated with rhodamine B released from S2 after 30 min of incubation with adulterated and non-adulterated sweet extract. Error bars are expressed as $3 \sigma$ for three independent experiments $\left({ }^{* *} p \leq 0.001\right)$

In summary, we have developed a first, rapid, highly selective and sensitive sensor for the fluorogenic detection of the synthetic drug 25I-NBOMe. The sensing material is synthetized using mesoporous silica nanoparticles loaded with rhodamine $\mathrm{B}$ (as a model fluorophore) and capped with $5-\mathrm{HT}_{2 \mathrm{~A}}$ receptor antibody through its interaction with the serotonin derivative 3 grafted onto the external surface of the material. Only in the presence of 25I-NBOMe, a remarkable release of rhodamine $B$ from the nanodevice is observed due to the 
detachment of the 5- $\mathrm{HT}_{2 \mathrm{~A}}$ receptor antibody from the nanoparticle surface due to its marked affinity toward the drug. Furthermore, solid $\mathbf{S} 2$ shows a highly selective response against 25I-NBOMe with a detection limit as low as $0.6 \mu \mathrm{M}$ in TRIS saline buffer. We also demonstrated that solid $\mathbf{S 2}$ can be used for the reliable identification "in situ" and "at site" of 25I-NBOMe in artificial saliva and adulterated sweets. We have taken advantage of the use of antibodies as a promising biomolecules for the preparation of custom-made nanodevices for sensing applications. The possibility to select a countless number of antibodies for a number of targets makes this approach highly appealing.

\section{Acknowledgements}

The authors thank the Spanish Government (projects RTI2018100910-B-C41 (MCUI/AEI/FEDER, UE) and CTQ2017-87954-P) and the Generalitat Valencia (PROMETEO/2018/024) for support. E. G. is grateful to the Spanish MEC for her FPU grant. The authors also thank the Electron Microscopy Service at the UPV for support.

Keywords: hallucinogenic drugs $\cdot 25 \mathrm{I}-\mathrm{NBOMe} \cdot$ smiles $\cdot$ agonist $5-\mathrm{HT}_{2 \mathrm{~A}}$ serotonin receptor $\cdot$ mesoporous silica nanoparticles

[1] a) World drug report. United Nations Office on Drugs and Crime (UNODC). Inform 2018; b) European drug report: Trends and Developments. European Monitoring Centre for Drugs and Drug Addition (EMCDDA). Inform 2018.

[2] a) D. Zuba, K. Sekula, A. Buczek, Forensic Sci. Int. 2013, 227, 7-14; b) J. L. Poklis, S. A. Raso, K. N. Alford, A. Poklis, M. R. Peace, J. Anal. Toxicol. 2015, 39, 617-623; c) Agenda item 4.19. Expert Committee on Drug Dependence. Thirty-sixth Meeting. Geneva, 16-20, June 2014 (World Health Organization).

[3] A. Batisse, N. Taright, C. Chevallier, M. Marillier, S. Djezzar, European Psychiatry 2016, 33, S72.

[4] A. Rickli, D. Luethi, J. Reinisch, D. Buchy, M. C. Hoener, M. E. Liechti, Neuropharmacology 2015, 99, 546-553.

[5] W. Lawn, M. Barratt, M. Williams, A. Horne, A. Winstock, J. Psychopharmacol. 2014, 28, 780-788.

[6] a) V. B. Kueppers, C. T. Cooke, Forensic Sci. Int. 2015, 249 , e15-e18;b) L. K. Laskowski, F. Elbakoush, J. Calvo, G. Exantus-Bernard, J. Fong, J. L. Poklis, A. Poklis, L. S. Nelson, 2015, 11, 237-241; c) K. G. Shanks, T. Sozio, G. S. Behonick, J. Anal. Toxicol. 2015, 39, 602-606.

[7] K. Francisco da Cunha, M. N. Eberlin, J. L. Costa, Forensic Toxicol. 2018, 36, 113-121.

[8] A. T. Caspar, A. G. Helfer, J. A. Michely, V. Auwaerter, S. D. Brandt, M. R. Meyer, H. H. Maurer, Anal. Bioanal. Chem. 2015, 407, 6697-6719.

[9] a) A. F. B. Andrade, S. K. Mamo, J. Gonzalez-Rodriguez, Anal. Chem. 2017, 89, 1445-1452; b) A. F. Belchior de Andrade, J. Gonzalez-Rodriguez, Analyst 2019, 144, 29652972.

[10] J. Coelho Neto, Forensic Sci. Int. 2015, 252, 87-92.

[11] X. Wu, C. Eriksson, A. Wohlfarth, J. Wallgren, R. Kronstrand, M. Josefsson, J. Dahlen, P. Konradsson, Tetrahedron 2017 73, 6393-6400.

[12] a) E. Aznar, M. Oroval, L. Pascual, J. R. Murguia, R. MartinezManez, F. Sancenon, Chem. Rev. 2016, 116, 561-718; b) I. I. Slowing, J. L. Vivero-Escoto, B. G. Trewyn, V. S. Y. Lin, J. Mater. Chem. 2010, 20, 7924-7937; c) E. Aznar, C. Coll, M. D. Marcos, R. Martínez-Máñez, F. Sancenón, J. Soto, P. Amorós,
J. Cano, E. Ruiz, Chem. Eur. J. 2009, 15, 6877-6888; d) A Ribes, E. Aznar, S. Santiago-Felipe, E. Pérez-Xifré, M. A. Tormo-Mas, J. Pemán, LI. F. Marsal, R. Martínez-Máñez, ACS Sens. 2019, 4, 1291-1298.

[13] a) C. Coll, A. Bernardos, R. Martinez-Manez, F. Sancenon, Acc. Chem. Res. 2013, 46, 339-349; b) F. Sancenon, L. Pascual, M. Oroval, E. Aznar, R. Martinez-Manez, ChemistryOpen 2015, 4, 418-437; c) E. Aznar, R. Villalonga C. Giménez, F. Sancenón, M. D. Marcos, R. Martínez-Máñez, P. Díez, J. M. Pingarrón, P. Amorós, Chem. Commun. 2013 49, 6391-6393; d) C. Giménez, C. de la Torre, M. Gorbe, E. Aznar, F. Sancenón, J. R. Murguía, R. Martínez-Máñez, M. D. Marcos, P. Amorós, Lagmuir 2015, 31, 3753-3762.

[14] a) J. S. Beck, J. C. Vartuli, W. J. Roth, M. E. Leonowicz, C. T. Kresge, K. D. Schmitt, C. T. W. Chu, D. H. Olson, E. W Sheppard, S. B. McCullen, J. B. Higgins, J. L. Schlenker, J. Am. Chem. Soc. 1992, 114, 10834-10843; b) W. Stoeber, A. Fink, E. Bohn, J. Colloid Interface Sci. 1968, 26, 62-69.

[15] H. Meng, Y. Liu, Y. Zhai, L. Lai, Eur. J. Med. Chem. 2013, 59, 160-167. 


\section{Table of Contents}

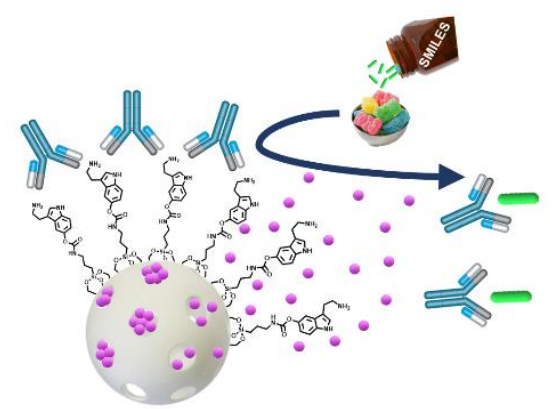

Detection of the potent abuse drug 25I-NBOMe was achieved using mesoporous silica nanoparticles loaded with rhodamine B, functionalized with a serotonin derivative and capped with the 5- $\mathrm{HT}_{2 \mathrm{~A}}$ receptor antibody. In the presence of the drug $5-\mathrm{HT}_{2 \mathrm{~A}}$ antibody was detached from the surface of the nanoparticles leading to rhodamine B release. The prepared solid allowed the sensitive and selective recognition of $25 \mathrm{I}-\mathrm{NBOMe}$ in artificial saliva and in sweets. 